\title{
Interaction of trivalent lanthanide cations with phosphoryl derivatives, amide, anisole, pyridine and triazine ligands: a quantum mechanics study
}

\author{
M. Baaden, F. Berny, C. Boehme, N. Muzet, R. Schurhammer, G. Wipff* \\ Laboratoire MSM, Institut de Chimie, Université Louis Pasteur, UMR CNRS 7551, 4, Rue B. Pascal, 67000 Strasbourg, France
}

\begin{abstract}
We report ab initio quantum mechanical calculations on charged $\mathbf{L M}^{3+}$ and neutral $\mathbf{L M C l}_{3}$ complexes formed by lanthanide $\mathbf{M}^{3+}$ cations $(\mathrm{M}=\mathrm{La}, \mathrm{Eu}, \mathrm{Yb})$ and model ligands $\mathbf{L}$, where $\mathbf{L}$ are phosphorous derivatives $\mathrm{R}_{3} \mathrm{PO}\left(\mathrm{R}=\right.$ alkyl $/ O$-alkyl/phenyl), $\mathrm{R}_{3} \mathrm{PS}_{\text {and }} \mathrm{R}_{2} \mathrm{PS}_{2}^{-}$ $(\mathrm{R}=\mathrm{alkyl} / \mathrm{phenyl})$, and amide, pyridine, triazine and anisole ligands. Among all neutral ligands studied, $\mathrm{Ph}_{3} \mathrm{PO}$ is intrinsically clearly the best. However, the comparison of $\mathbf{L M}^{3+}$ to $\mathbf{L} \mathbf{M C l}_{3}$ complexes demonstrates that the concept of 'ligand basicity' is not sufficient to compare the efficiency of cation coordination. Counterions play an important role in the structures of the complexes and for the consequences of substitution in the ligand. For instance, in the absence of competing interactions, phenyl substituted $\mathrm{R}_{3} \mathrm{PS}_{\mathrm{S}}$ or $\mathrm{R}_{2} \mathrm{PS}_{2}^{-}$ ligands interact better than alkyl substituted ones, but the order is reversed in the presence of counterions. Counterions also amplify the alkyl vs. $O$-alkyl substituent effect in $\mathrm{R}_{3} \mathrm{PO}$ complexes. Bidentate anions or more bulky anions are expected to amplify the effects observed with chloride anions. Thus, multiple interactions between counterions and the other species in the first coordination sphere markedly contribute to the 'effectiveness' and stereochemistry of ligand-cation interactions. (C) 2000 Elsevier Science S.A. All rights reserved.
\end{abstract}

Keywords: Lanthanides; Ionophores; Liquid-liquid ion extraction

\section{Introduction}

The search for complexant molecules which specifically bind lanthanides and actinides and separate them from other cations may be guided by an assessment of the intrinsic energetic and stereochemical features of the cation-ligand interactions 'in the gas phase', i.e. in the absence of any other competing factor [1-3]. Gas phase data on simple systems contribute to a better understanding, by comparison, of what happens in solution with more complex ones $[4,5]$. In the case of trivalent lanthanide or actinide ions, such data are not available. Quantum mechanical (QM) computations offer an alternative source of valuable information on structural, electronic and energy features of non-covalent interactions [6]. In this paper, we report on recent $\mathrm{QM}$ ab initio results on the interaction between $\mathrm{M}^{3+}$ lanthanide cations ( $\mathrm{M}=\mathrm{La}$ vs. $\mathrm{Eu}$ vs. $\mathrm{Yb}$ ) and important types of ligands $\mathbf{L}$ : phosphorous derivatives of $\mathrm{R}_{3} \mathrm{PO}\left(\mathrm{R}=\right.$ alkyl $/ O$-alkyl/phenyl), $\mathrm{R}_{3} \mathrm{PS}, \mathrm{R}_{2} \mathrm{PS}_{2}^{-}(\mathrm{R}=$ alkyl/phenyl) type, and amide, pyridine, triazine and anisole ligands (Figs. 1-3). We first consider the charged

*Corresponding author.

E-mail address: wipff@chimie.u-strasbg.fr (G. Wipff)
1:1 $\mathbf{L M}^{3+}$ complexes and calculate the corresponding interaction energies $\Delta E$ between $\mathbf{L}$ and $\mathrm{M}^{3+}$ in the absence of other competing interactions. In addition, the effect of neutralizing counterions is investigated for $\mathbf{L M C l}_{3}$ complexes, which are closer to those expected in condensed phases, both in terms of metal cation effective charge and coordination number. Indeed, in liquid-liquid extraction experiments, the cation is neutralized by accompanying counterions. In solid state structures, most of the lanthanide and actinide cations are also coordinated by neutralizing counterions. Our aim is to compare the $\Delta E$ values of a given cation and these ligands $\mathbf{L}$. The amide and pyridine complexes are described in Ref. [7]. Some results for $\mathbf{L}=\mathrm{Me}_{3} \mathrm{PO}$ and $\mathrm{Ph}_{3} \mathrm{PO}$ have been reported by Troxler et al. [8] but they have been reoptimized in order to allow for a consistent comparison with the other ligands. A detailed analysis of $\mathrm{R}_{3} \mathrm{PS}, \mathrm{R}_{2} \mathrm{PS}_{2}^{-}$and $(\mathrm{MeO})_{3} \mathrm{PO}$ complexes can be found in Refs. [9-11].

\section{Methods}

The QM ab initio calculations were performed at the HF level using the Gaussian-94 [14] and Gaussian-98 pack- 


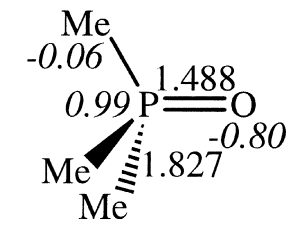

$$
\mu=4.9 \mathrm{D}, \text { Eprot }=-239.1
$$

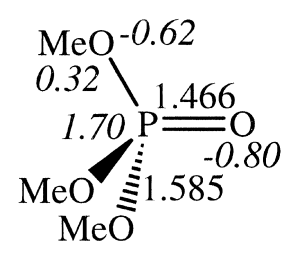

$$
\mu=1.0 \mathrm{D}, \text { Eprot }=-223 .
$$$$
\mu=4.9 \mathrm{D}, \text { Eprot }=-248.1
$$
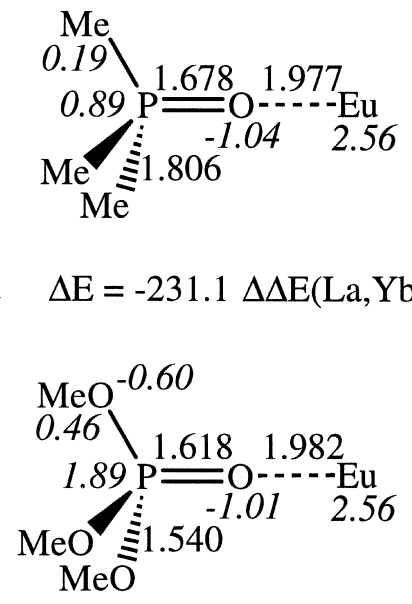

$$
\Delta \mathrm{E}=-231.1 \Delta \Delta \mathrm{E}(\mathrm{La}, \mathrm{Yb})=-39.6
$$

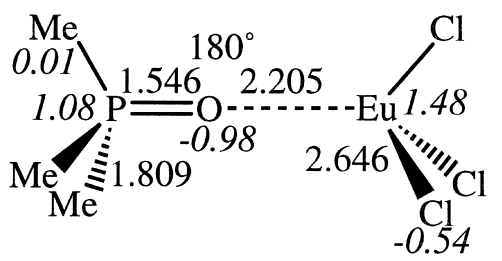

$\Delta \mathrm{E}=-44.6 \Delta \Delta \mathrm{E}(\mathrm{La}, \mathrm{Yb})=-6.5$

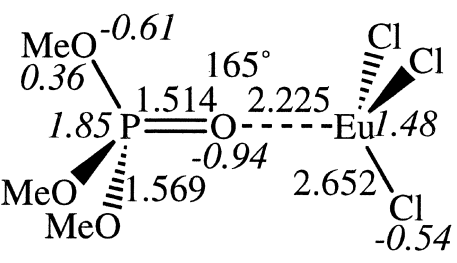

$\Delta \mathrm{E}=-226.0 \Delta \Delta \mathrm{E}(\mathrm{La}, \mathrm{Yb})=-39.1$

$\Delta \mathrm{E}=-25.9 \quad \Delta \Delta \mathrm{E}(\mathrm{La}, \mathrm{Yb})=-5.8$

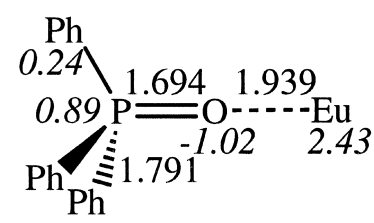

$\Delta \mathrm{E}=-275.3 \Delta \Delta \mathrm{E}(\mathrm{La}, \mathrm{Yb})=-45.4$

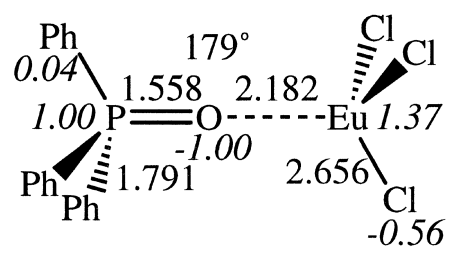

$\Delta \mathrm{E}=-57.8 \quad \Delta \Delta \mathrm{E}(\mathrm{La}, \mathrm{Yb})=-6.6$
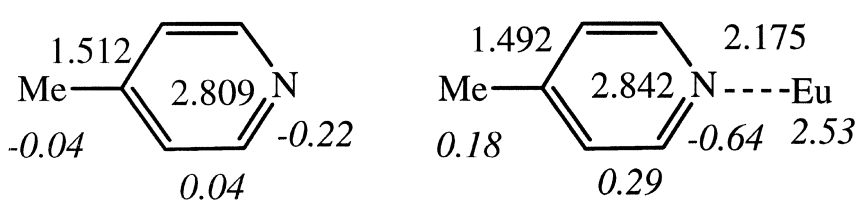

$\mu=2.9 \mathrm{D}$, Eprot $=-240.4$

$\Delta \mathrm{E}=-173.6 \Delta \Delta \mathrm{E}(\mathrm{La}, \mathrm{Yb})=-37.0$

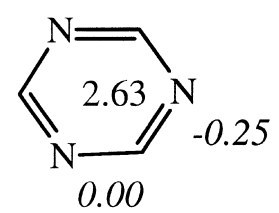

$\mu=0.0 \mathrm{D}$, Eprot $=-216.9$

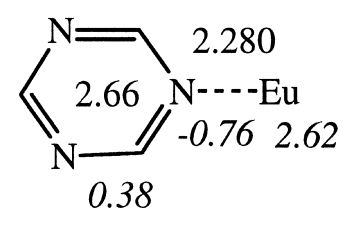

$$
\Delta \mathrm{E}=-123.4
$$

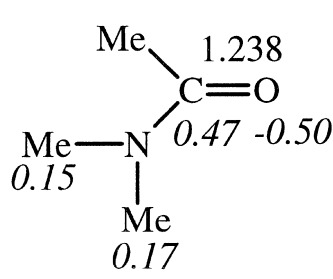

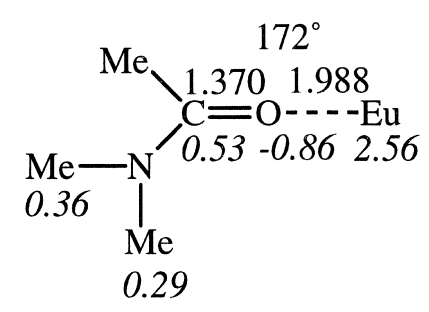

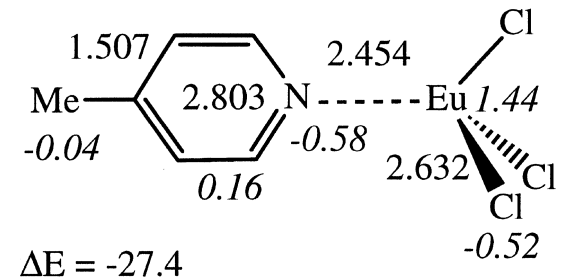

$\Delta \mathrm{E}=-27.4$
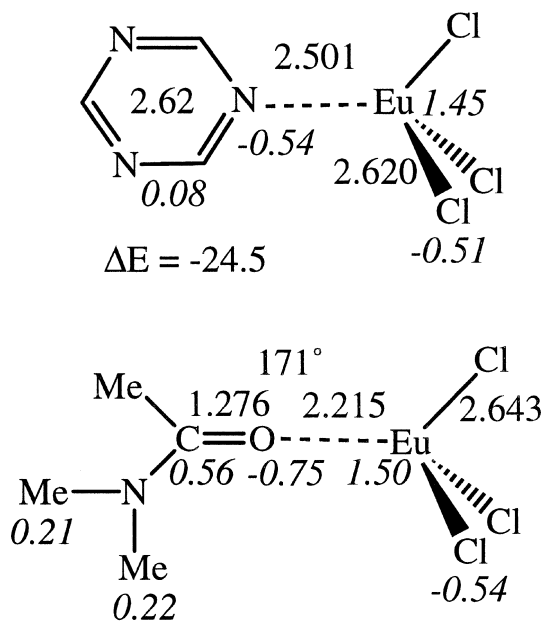

$$
\mu=1.3 \mathrm{D}, \text { Eprot }=-232.8 \quad \Delta \mathrm{E}=-209.0 \quad \Delta \Delta \mathrm{E}(\mathrm{La}, \mathrm{Yb})=-38.6 \quad \Delta \mathrm{E}=-46.2 \quad \Delta \Delta \mathrm{E}(\mathrm{La}, \mathrm{Yb})=-6.4
$$

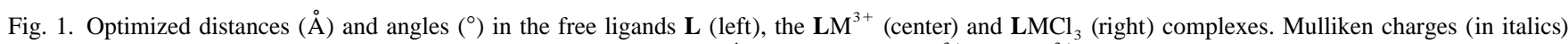
on selected fragments or atoms. $\Delta E$ is the interaction energy $\left(\mathrm{kcal} \mathrm{mol}^{-1}\right.$ ) between $\mathbf{L}$ and $\mathrm{Eu}^{3+}$ (in $\mathbf{L E u}^{3+}$ complexes) or between $\mathbf{L}$ and $\mathbf{E u C l}_{3}$ (in $\mathbf{L E u C l}{ }_{3}$ complexes). $\Delta \Delta E(\mathrm{La}, \mathrm{Yb})$ is the difference in the interaction energies calculated in the corresponding $\mathrm{Yb}^{3+}$ and $\mathrm{La}^{3+}$ complexes. $\left(\mathbf{L}=\mathrm{Me}{ }_{3} \mathrm{PO} ;(\mathrm{MeO}){ }_{3} \mathrm{PO}\right.$; $\mathrm{Ph}_{3} \mathrm{PO}$; Me-pyridine; 1,3,5-triazine; $N, N$-dimethylacetamide.) 


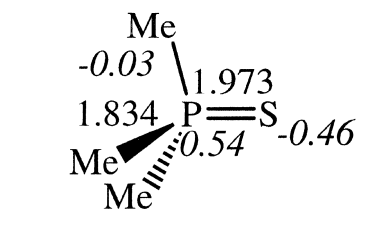

$\mu=5.5 \mathrm{D}$, Eprot $=-223.4$

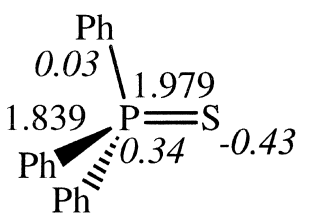

$\mu=5.4 \mathrm{D}$, Eprot $=-233.6$

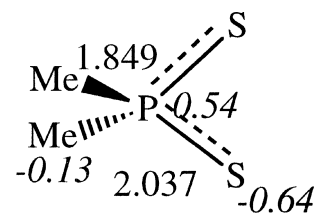

$\mu=5.3 \mathrm{D}$, Eprot $=-331.3$

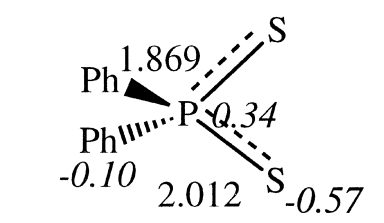

$\mu=9.2 \mathrm{D}$, Eprot $=-323.8$

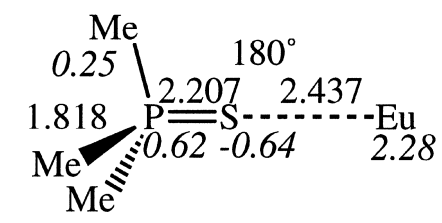

$\Delta \mathrm{E}=-204.0 \Delta \Delta \mathrm{E}(\mathrm{La}, \mathrm{Yb})=-36.1$

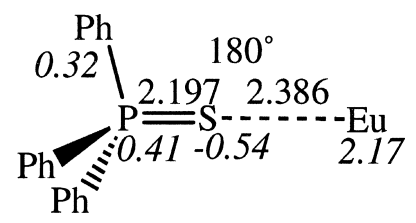

$\Delta \mathrm{E}=-226.6 \Delta \Delta \mathrm{E}(\mathrm{La}, \mathrm{Yb})=-40.1$

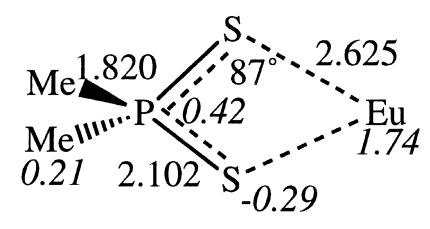

$\Delta \mathrm{E}=-522.8 \Delta \Delta \mathrm{E}(\mathrm{La}, \mathrm{Yb})=-57.1$

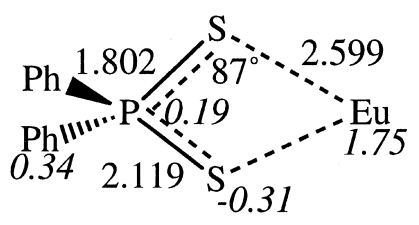

$\Delta \mathrm{E}=-531.5 \Delta \Delta \mathrm{E}(\mathrm{La}, \mathrm{Yb})=-65.2$

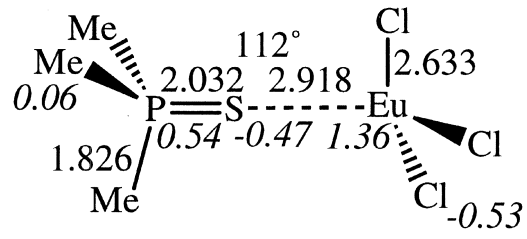

$\Delta \mathrm{E}=-37.5 \Delta \Delta \mathrm{E}(\mathrm{La}, \mathrm{Yb})=-2.7$

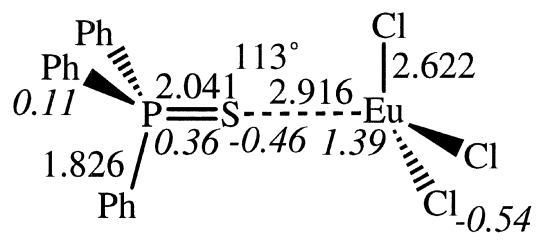

$\Delta \mathrm{E}=-36.2 \quad \Delta \Delta \mathrm{E}(\mathrm{La}, \mathrm{Yb})=-2.0$

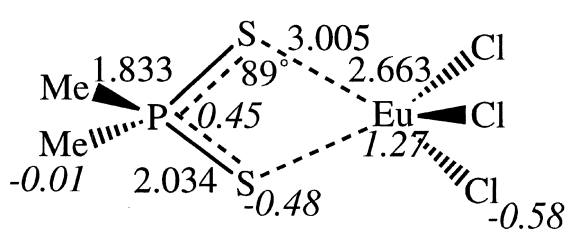

$\Delta \mathrm{E}=-82.4 \Delta \Delta \mathrm{E}(\mathrm{La}, \mathrm{Yb})=+1.3$

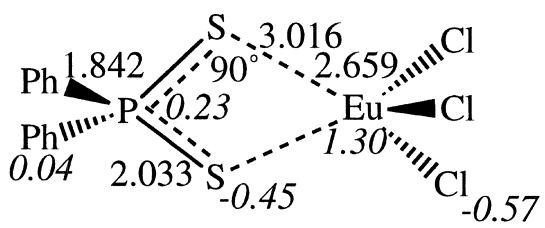

$\Delta \mathrm{E}=-75.6 \Delta \Delta \mathrm{E}(\mathrm{La}, \mathrm{Yb})=+1.6$

Fig. 2. See definitions in Fig. 1. $\mathbf{L}=\mathrm{Me}_{3} \mathrm{PS} ; \mathrm{Ph}_{3} \mathrm{PS} ; \mathrm{Me}_{2} \mathrm{PS}_{2}^{-} ; \mathrm{Ph}_{2} \mathrm{PS}_{2}^{-}$.

ages [15]. The $46+4 \mathrm{f}^{\mathrm{n}}$ core electrons of the lanthanide cations were described by the quasi-relativistic effective core potential (ECP) of Dolg et al. $[16,17]$ and the valence electrons by a $(7 \mathrm{~s}, 6 \mathrm{p}, 5 \mathrm{~d}) /[5 \mathrm{~s}, 4 \mathrm{p}, 3 \mathrm{~d}]$ Gaussian basis set supplemented by one $\mathrm{f}$ polarization function of exponent 0.591 [18]. The H, C, N, O, S and P atoms were described by the standard Dunning-Hay double- $\zeta$ basis set [19] including one $3 \mathrm{~d}$ polarization function on the $\mathrm{P}$ atom (of exponent $\left.\zeta_{3 \mathrm{~d}}=0.37\right)$ and on the $\mathrm{S}$ atom $\left(\zeta_{3 \mathrm{~d}}=0.532\right)$ (referred to hereafter as 'DZ' basis set). In additional calculations, polarization functions on the atoms of $\mathbf{L}$ and on $\mathrm{Cl}$ atoms were also included (exponents being $\zeta_{3 \mathrm{dC}}=$ $\left.0.75, \quad \zeta_{3 \mathrm{dO}}=0.85, \quad \zeta_{3 \mathrm{dN}}=0.80, \quad \zeta_{2 \mathrm{pH}}=0.80, \quad \zeta_{3 \mathrm{dCl}}=0.60\right)$, leading to the $\mathrm{DZ}^{*}$ basis set.

The $\mathrm{R}_{3} \mathrm{PS}$ and $\mathrm{R}_{2} \mathrm{PS}_{2}^{-}$ligands and the corresponding complexes were fully optimized using analytical gradients and the DZ* basis set. The other ligands and their protonated forms $\mathbf{L H}^{+}$were similarly optimized with the DZ* basis set. Their $\mathbf{L M}^{3+}$ and $\mathbf{L M C l}{ }_{3}$ complexes were optimized with the DZ basis set as described in Refs. $[9,10]$ and the corresponding interaction energies $\Delta E$, Mulliken charges and dipole moments were recalculated with the $\mathrm{DZ}^{*}$ basis set.

The interaction energies $\Delta E$ of the ligands were calculated as $\Delta E=E\left(\mathbf{L M}^{3+}\right)-E(\mathbf{L})-E\left(\mathrm{M}^{3+}\right)$ in the $\mathbf{L M}^{3+}$ complexes, and as $\Delta E=E\left(\mathbf{L M C l}_{3}\right)-E(\mathbf{L})-E\left(\mathrm{MCl}_{3}\right)$ in the $\mathbf{L M C l}_{3}$ complexes, using all optimized corresponding geometries. The basis set superposition error ('BSSE') was estimated in typical cases using the counterpoise method [20]. As the BSSE was small and nearly constant (from 


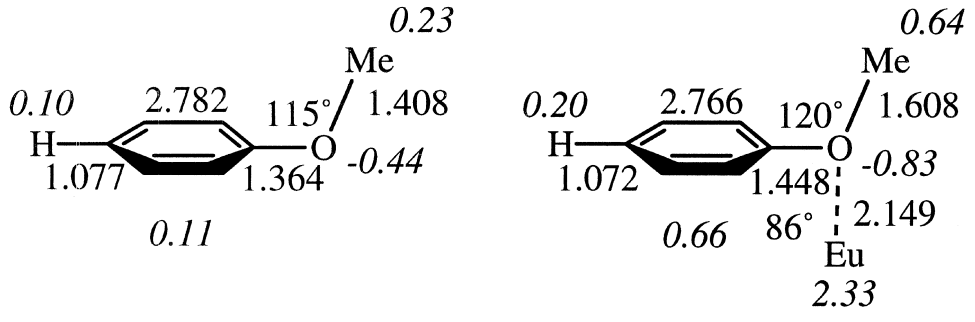

$\mu=1.6 \mathrm{D}$, Eprot $=-200.9$

$$
\Delta \mathrm{E}=-182.4 \Delta \Delta \mathrm{E}(\mathrm{La}, \mathrm{Yb})=-41.7
$$

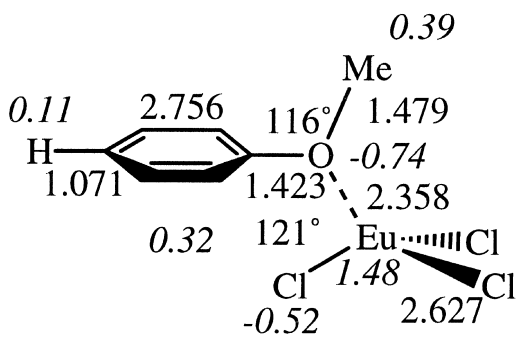

$\Delta \mathrm{E}=-29.1$

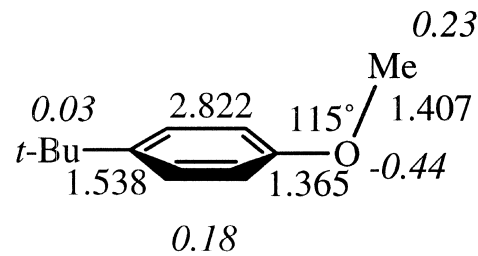

0.18

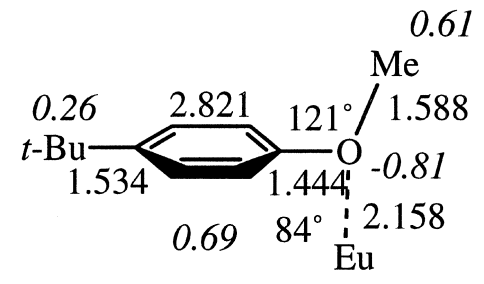

2.25

$$
\mu=1.7 \mathrm{D}, \text { Eprot }=-198.3
$$

$$
\Delta \mathrm{E}=-198.8 \Delta \Delta \mathrm{E}(\mathrm{La}, \mathrm{Yb})=-42.6
$$

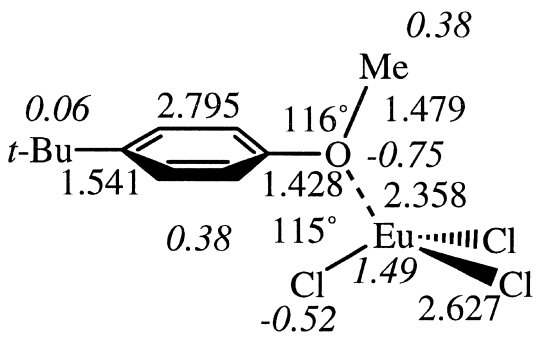

Fig. 3. See definitions in Fig. 1. $\mathbf{L}=$ Anisole; $t$-Bu-anisole.

-2 to $-4 \mathrm{kcal} \mathrm{mol}^{-1}$ ), we report the uncorrected $\Delta E$ values for simplicity.

\section{Results and discussion}

The most important energy, structural (distances and angles) and electronic (atomic charges) results are summarized in Figs. 1-3. For any given ligand $\mathbf{L}, \Delta E$ in the $\mathbf{L M}^{3+}$ complexes increases with the cation hardness $\left(\mathrm{La}^{3+}<\mathrm{Eu}^{3+}<\mathrm{Yb}^{3+}\right)$. This is why, for simplicity, we primarily discuss complexes with $\mathrm{Eu}^{3+}$, which is the cation of intermediate size, and report the corresponding $\Delta E$, as well as the $\Delta \Delta E(\mathrm{La}, \mathrm{Yb})$ energy difference between the $\mathrm{La}^{3+}$ and $\mathrm{Yb}^{3+}$ complexes, which measures the "cation selectivity' of a given ligand $\mathbf{L}$. A graphical representation of $\Delta E$ values and protonation energies $E_{\text {prot }}$ of $\mathbf{L}$ is given in Fig. 5.

Depending on the nature of the dominant electrostatic interactions calculated, the $\Delta E$ values fall in three categories. The strongest interactions are of charge-charge type $\left(\mathrm{R}_{2} \mathrm{PS}_{2}^{-}-\mathrm{M}^{3+} ; \Delta E\right.$ is about $\left.530 \mathrm{kcal} \mathrm{mol}^{-1}\right)$. They are followed by charge-dipole interactions in $\mathbf{L M}^{3+}$ complexes with the neutral ligands (from 123 to 280 $\mathrm{kcal} \mathrm{mol}{ }^{-1}$ ) and to a lesser extent in the $\mathrm{R}_{2} \mathrm{PS}_{2}^{-}-\mathrm{MCl}_{3}$ complexes with the charged ligands (about $80 \mathrm{kcal} \mathrm{mol}^{-1}$ ), and finally by dipole-dipole interactions in $\mathbf{L M C l}_{3}$ complexes with neutral ligands (from 25 to $46 \mathrm{kcal} \mathrm{mol}^{-1}$ ). Among the $\mathbf{L M}^{3+}$ complexes with neutral ligands, $\Delta E$ decreases in the order $\mathrm{Ph}_{3} \mathrm{PO}>\mathrm{Me}_{3} \mathrm{PO}>\mathrm{Ph}_{3} \mathrm{PS}$,
$(\mathrm{MeO})_{3} \mathrm{PO}>$ amide $>\mathrm{Me}_{3} \mathrm{PS}>t-\mathrm{Bu}$ - anisole $>$ anisole $>$ pyridine $>$ triazine in the $\mathbf{L M}^{3+}$ complexes. The sequence is somewhat different in the corresponding $\mathbf{L M C l}_{3}$ complexes $\left(\mathrm{Ph}_{3} \mathrm{PO}>\right.$ amide, $\mathrm{Me}_{3} \mathrm{PO}>\mathrm{Me}_{3} \mathrm{PS}, \mathrm{Ph}_{3} \mathrm{PS}>t$-Buanisole $>$ anisole $>$ pyridine $>(\mathrm{MeO})_{3} \mathrm{PO}>$ triazine $)$, showing that counterions may modulate or reverse the order of interaction energies. We notice that differences in $\Delta E$ values in the $\mathbf{L M C l}_{3}$ series are small, and may be changed by substituents, as well as by subtle geometry modifications.

Although the definition of atomic charges is somewhat arbitrary and numerical values are basis set dependent, one observes (Figs. 1-3) important electron transfer to the cation. Its positive charge is about $2.3 e$ to $2.6 e$ in $\mathbf{L E u}^{3+}$ ( $\mathbf{L}=\mathrm{R}_{3} \mathrm{PO}$, amide, anisole, pyridine, triazine), $2.2 e$ in $\mathrm{R}_{3} \mathrm{PSEu}^{3+}, 1.7 e$ in $\mathrm{R}_{2} \mathrm{PS}_{2} \mathrm{Eu}^{2+}$, and $1.3 e$ to $1.5 e$ in the neutral $\mathbf{L E u C l}_{3}$ complexes. There is, however, no simple relation between the charge transfer to the cation and the corresponding interaction energies $\Delta E$, nor between the permanent dipole moment of the free ligands $\mathbf{L}$ and the $\Delta E$ values (Figs. 1-3).

In the following, we first discuss the interaction energies $\Delta E$ and structural features of the phosphoryl $\mathrm{R}_{3} \mathrm{PO}$ complexes with $\mathrm{Eu}^{3+}$ and $\mathrm{EuCl}_{3}$. We compare how the different substituents $\mathrm{R}$ influence the $\Delta E$ values in the absence and in the presence of counterions. We also address the cation discrimination of the ligands in terms of the differences in interaction energies $\Delta \Delta E(\mathrm{La}, \mathrm{Yb})$ between the largest and the smallest cation studied. The final part covers how the thiophosphoryl $\left(\mathrm{R}_{3} \mathrm{PS}\right)$, dithiophosphi- 
nate $\left(\mathrm{R}_{2} \mathrm{PS}_{2}^{-}\right)$, amide, anisole and pyridine complexes differ from the phosphoryl complexes from an energetic and from a structural point of view. The calculated $\Delta E$ values and protonation energies of the ligands are shown in Figs. 1-3.

\subsection{Complexes with phosphoryl $R_{3} P=O$ ligands $(R=$ alkyl/phenyl/O-alkyl)}

The coordination of the phosphoryl ligands to a 'naked' $\mathrm{Eu}^{3+}$ cation leads to very high dipole-charge interaction energies of more than $200 \mathrm{kcal} \mathrm{mol}^{-1}$. In the process of coordination the ligand is strongly polarized (see Fig. 4) by the neighboring charge, as can be seen from the lengthening of the $\mathrm{P}-\mathrm{O}$ bond. In the free $\mathrm{Ph}_{3} \mathrm{PO}$ ligand, for example, the $\mathrm{P}-\mathrm{O}$ bond length is $1.510 \AA$ A, corresponding to a partial double bond. In the $\mathrm{Ph}_{3} \mathrm{POEu}^{3+}$ complex, electron density is moved from the $\mathrm{P}-\mathrm{O}$ bond to the oxygen atom, resulting in a $\mathrm{P}-\mathrm{O}$ single bond with a length of $1.694 \AA$. This effect can also be seen in the oxygen charge, which becomes more negative. Such an increase of negative charge on the connecting atom from the free to the complexed ligand is found for all complexes with neutral ligands, showing that the electron transfer to the metal stems from more remote atoms.
The pronounced ligand polarization is the key to understanding the influence of the substituents $\mathrm{R}$ on the $\Delta E$ values. Phenyl is the largest and most polarizable substituent. Therefore, $\mathrm{Ph}_{3} \mathrm{PO}$ yields the strongest ligandmetal interaction, nearly $50 \mathrm{kcal} \mathrm{mol}^{-1}$ more than the next best ligand, $\mathrm{Me}_{3} \mathrm{PO}$. Substituting methyl for the more electronegative methoxy group gives the expected lowering of $\Delta E$, but the effect is surprisingly small (only 5 $\mathrm{kcal} \mathrm{mol}^{-1}$ ). The change in the electronegativity of $\mathrm{R}$ from the methoxy to the methyl group has a smaller effect than the change of polarizability from methyl to phenyl.

The interaction energies of the discussed ligands are strongly dependent on the cation size. The $\Delta \Delta E(\mathrm{La}, \mathrm{Yb})$ value is about $40 \mathrm{kcal} \mathrm{mol}^{-1}$ for all $\mathrm{R}_{3} \mathrm{PO}$ ligands. The $\Delta \Delta E$ values follow the trend of the $\Delta E$ values, i.e. the largest cation discrimination is observed with phenyl as substituent. This substituent effect is small, however. The difference between phenyl and methoxy groups in this respect is only about $6 \mathrm{kcal} \mathrm{mol}^{-1}$.

The addition of counterions to the metal cation leads to a marked drop in $\Delta E$, by a factor of 5.2 with $\mathrm{Me}_{3} \mathrm{PO}$, of 4.8 with $\mathrm{Ph}_{3} \mathrm{PO}$ and of 8.7 with $(\mathrm{MeO})_{3} \mathrm{PO}$. Upon addition of counterions the hard dipole-charge interaction is substituted by a weaker and softer dipole-dipole interaction. This shows in a less pronounced polarization of the ligand which in turn leads to a less pronounced change of its

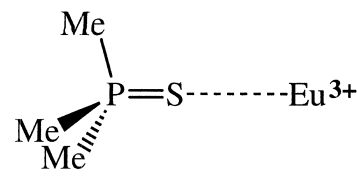<smiles>C[P+](C)(C)[S-]C[18CH]</smiles><smiles>C[P+](C)(C)SCBr</smiles><smiles>CC(C)[14CH2]S[P](c1ccccc1)(c1ccccc1)c1ccccc1</smiles>

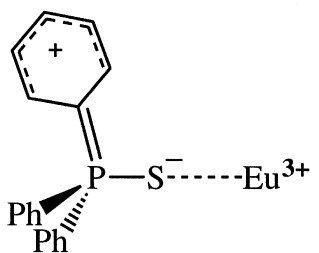<smiles></smiles><smiles></smiles><smiles>C[c+]1ccn([18CH2])cc1</smiles><smiles>CCCCn1cc[c+](C)cc1</smiles><smiles>CC(=O)N(C)C</smiles><smiles>CC([O+]C[18CH])=[N+](C)C</smiles><smiles>CC(OC(C)C)=[N+](C)C</smiles>

Fig. 4. Schematic representation of $\mathbf{L M}^{3+}$ complexes, which highlight the interactions between the cation and the unperturbed ligand (left), the polarization of $\mathbf{L}$ by the cation (center) and the covalent character of the Ligand-Metal bond (right). 
structure. For example, the $\mathrm{P}-\mathrm{O}$ bond elongation from the free to the complexed ligand is only $0.05 \AA$ in $\mathrm{Ph}_{3} \mathrm{POEuCl}_{3}$ compared to $0.18 \AA$ in $\mathrm{Ph}_{3} \mathrm{POEu}^{3+}$. The connecting oxygen atom is also more negatively charged than in the free ligand. For $\mathrm{Ph}_{3} \mathrm{PO}$, the oxygen charge changes by -0.22 in the $\mathbf{L M}^{3+}$ complex and by -0.20 in the $\mathbf{L M C l}_{3}$ complex. The occurrence of covalent effects can be seen from the slight bending about the oxygen atom in some neutral complexes, which can be explained by bonding orbital directionality. Changing the type of ligand-metal interactions also reduces the influence of the substituents $\mathrm{R}$ on $\Delta E$ values. In fact, the phenyl substituted ligand $\mathrm{Ph}_{3} \mathrm{PO}$ still yields a higher interaction energy with $\mathrm{MCl}_{3}$ than the alkyl-substituted $\mathrm{Me}_{3} \mathrm{PO}$, but the difference drops to about $13 \mathrm{kcal} \mathrm{mol}^{-1}$. The high polarizability of the phenyl ligand is less important here. Furthermore, $\Delta E$ is negatively influenced by phenyl-chloride repulsions and the higher electronegativity of the phenyl compared to the methyl carbon. The effects of ligand-counterion repulsions and ligand electronegativity also show in the huge difference in $\Delta E$ (about $20 \mathrm{kcal} \mathrm{mol}^{-1}$ ) between $\mathrm{Me}_{3} \mathrm{POMCl}_{3}$ and $(\mathrm{MeO})_{3} \mathrm{POMCl}_{3}$ complexes. Along with the decrease of $\Delta E$ in the neutral complexes the cation discriminating capabilities of the ligands also decrease, with $\Delta \Delta E(\mathrm{La}, \mathrm{Yb})$ dropping from $40 \mathrm{kcal} \mathrm{mol}^{-1}$ in the charged $\mathbf{L M}^{3+}$ to about $6 \mathrm{kcal} \mathrm{mol}^{-1}$ in the neutral $\mathbf{L M C l}_{3}$ complexes. Substituent effects on cation discrimination are negligible here.

\subsection{Complexes with neutral ligands: thiophosphoryl $R_{3} P S$, amide, pyridine, 1,3,5-triazine and anisole}

In the $\mathrm{LEu}^{3+}$ complexes with neutral monodentate ligands, none yields a $\Delta E$ interaction as strong as the phosphoryl ligands. The amide and the best studied thiophosphoryl $\left(\mathrm{Ph}_{3} \mathrm{PS}\right)$ ligand yield $\Delta E$ values of 209 and $225 \mathrm{kcal} \mathrm{mol}^{-1}$, respectively, compared to about 280 kcal mol ${ }^{-1}$ in $\mathrm{Ph}_{3} \mathrm{POEu}^{3+}$. The unsubstituted anisole interacts better than the pyridine (182 and $174 \mathrm{kcal} \mathrm{mol}^{-1}$, respectively), while its $t$-butyl derivative interacts only 10 $\mathrm{kcal} \mathrm{mol}^{-1}$ less than the amide, revealing a marked para substituent effect (of about $16 \mathrm{kcal} \mathrm{mol}^{-1}$ ). The triazine (123 kcal mol ${ }^{-1}$ ) ligand yields the lowest $\Delta E$, which is 51 $\mathrm{kcal} \mathrm{mol}^{-1}$ less than with pyridine, as a result of the zero dipole moment of triazine, and of the higher electronegativity and lower polarizability of the two additional nitrogen atoms in its ring system.

The phenyl vs. alkyl substituent effects on $\Delta E$ values follow the same order for the thiophosphoryl and amide complexes as observed for the phosphoryl ones. In the $\mathbf{L E u}^{3+}$ complexes, $\mathrm{Ph}_{3}$ PS yields a $\Delta E$ about $20 \mathrm{kcal} \mathrm{mol}^{-1}$ higher than $\mathrm{Me}_{3} \mathrm{PS}$ and the $\mathrm{HPh}$-amide ligand gives a $\Delta E$ about $8 \mathrm{kcal} \mathrm{mol}^{-1}$ higher than the HMe-amide [9]. This is less than the difference between the $\mathrm{Ph}_{3} \mathrm{PO}$ and $\mathrm{Me}_{3} \mathrm{PO}$ complexes (about $50 \mathrm{kcal} \mathrm{mol}^{-1}$ ).
The addition of counterions to the $\mathbf{L M}^{3+}$ complexes leads to a drop of the $\Delta E$ values, and a lengthening of the metal-ligand bond distances. In addition, for the $\mathrm{R}_{3} \mathrm{PSMCl}_{3}$ complexes, Fig. 2 reveals two important effects. First, the order of alkyl vs. phenyl substituents is reversed, i.e. $\Delta E$ is smaller (by about $1 \mathrm{kcal} \mathrm{mol}^{-1}$ ) in the $\mathrm{Ph}_{3} \mathrm{PSEuCl}_{3}$ complex than in the $\mathrm{Me}_{3} \mathrm{PSEuCl}_{3}$ complex. The second feature concerns the marked soft and covalent character of the metal-sulfur bond, which leads to a pronounced bending at the sulfur atom (about $112^{\circ}$; see Fig. 2). This bending makes sulfur-based organophosphorous compounds excellent candidates for bidentate ligands in which binding coordination has to be bent. As bonding in actinide complexes is generally more covalent than in lanthanide ones, discrimination of actinides is expected to be enhanced with thiophosphoryl bidentate ligands.

\subsection{Complexes with negatively charged dithiophosphinate $\left(\mathrm{R}_{2} \mathrm{PS}_{2}^{-}\right)$ligands}

With the naked $\mathrm{Eu}^{3+}$ cation, $\mathrm{R}_{2} \mathrm{PS}_{2}^{-}$ligands yield interaction energies of more than $520 \mathrm{kcal} \mathrm{mol}^{-1}$, the latter being higher with $\mathrm{R}=$ phenyl than with $\mathrm{R}=$ methyl. The difference, however, is smaller (about $9 \mathrm{kcal} \mathrm{mol}^{-1}$ ) than with the neutral ligands, as a charge-charge interaction is less influenced by the choice of substituents and polarization effects are relatively less important. The addition of three counterions to the metal leads to negatively charged complexes $\mathrm{R}_{2} \mathrm{PS}_{2} \mathrm{EuCl}_{3}^{-}$. The corresponding $\Delta E$ values (about $80 \mathrm{kcal} \mathrm{mol}^{-1}$ ) are about $40 \mathrm{kcal} \mathrm{mol}^{-1}$ higher than for the $\mathrm{R}_{3} \mathrm{PS}$ and $\mathrm{R}_{3} \mathrm{PO}$ complexes, which represents the gain of charged vs. neutral ligands and of bidentate vs. monodentate bonding.

It is interesting that in the dithiophosphinate complexes the charge on the connecting (sulfur) atoms becomes more positive upon complexation, the effect being opposite to that found for all neutral ligands. Furthermore, the positive charge on the metal atom decreases more than with the neutral ligands, especially in the complexes without counterions. This is related to an increased charge-transfer to the metal, which is facilitated by the negative charge on $\mathbf{L}$ and better orbital overlap in the bent structure. As with the $\mathrm{R}_{3} \mathrm{PS}$ complexes, the order of alkyl vs. phenyl substituent effects is reversed when counterions are added to the system. The cation discrimination behavior in the $\mathrm{R}_{2} \mathrm{PS}_{2} \mathrm{MCl}_{3}^{-}$complexes is also very interesting: the large La cation is bonded stronger than the small $\mathrm{Yb}$ (by 1-2 $\mathrm{kcal} \mathrm{mol}^{-1}$ ). Whether this is a result of ligand-ligand repulsion or a more subtle ligand interaction effect is a matter of ongoing research.

\section{Conclusion}

Quantum mechanical studies on the interactions between lanthanide cations and typical ligand molecules provide 


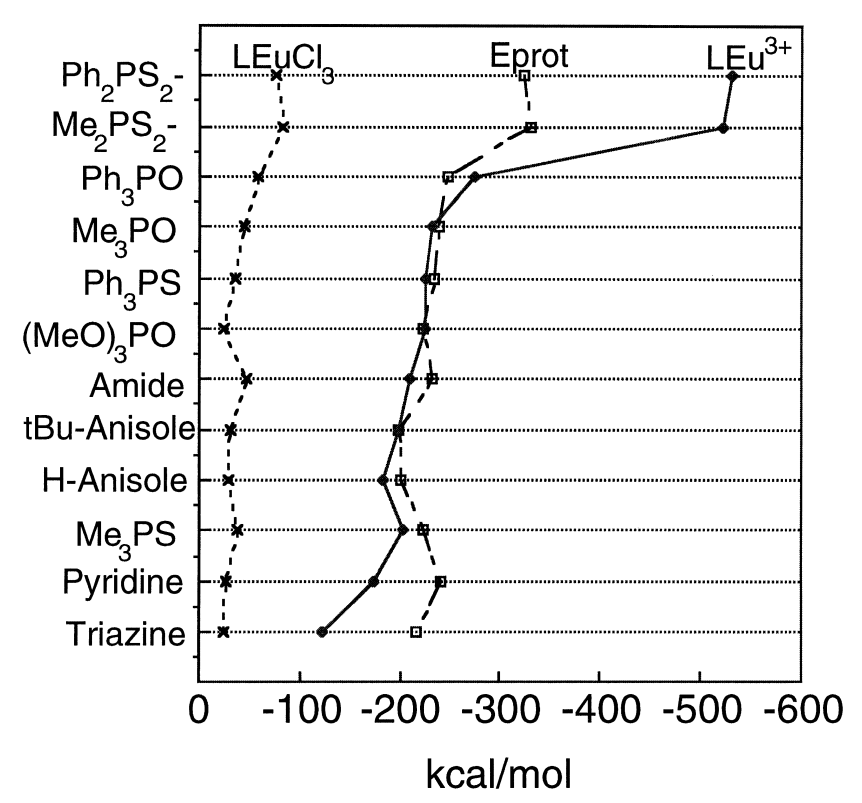

Fig. 5. Graphical representation of calculated interaction energies $\Delta E$ in the $\mathbf{L E u}^{3+}$ and $\mathbf{L E u C l}_{3}$ systems, and protonation energies $\left(E_{\text {prot }}\right)$ of $\mathbf{L}$ (kcal mol ${ }^{-1}$ ).

important insights into their intrinsic structural and energy features. A graphical representation of the results is given in Fig. 5.

Intrinsically, for any ligand (i.e. without counterions), the interaction energies $\Delta E$ values increase as expected with the cation hardness (from $\mathrm{La}^{3+}$ to $\mathrm{Yb}^{3+}$ ). Among the neutral ligands studied here, phosphoryl ligands give the largest interaction energies $\Delta E$. Following are the amide, thiophosphoryl, anisole and pyridine ligands. The triazine ligand, which mimics the central moiety of TPTZ [21] is markedly weaker bound than the others. The negatively charged bidentate dithiophosphinate ligands which model CYANEX 301 molecules [22-24], yield higher $\Delta E$ values than the neutral ligands. We notice however that the differences in $\Delta E$ values for $\mathbf{L M}^{3+}$ complexes with neutral ligands such as $\mathrm{Ph}_{3} \mathrm{PS}, \mathrm{Me}_{3} \mathrm{PO},(\mathrm{MeO})_{3} \mathrm{PO}$, amide and anisole are smaller than the changes in $\Delta E$ values related to substituent effects in some ligands (about $50 \mathrm{kcal} \mathrm{mol}^{-1}$ for $\mathrm{Ph}$ vs. Me substituents in $\mathrm{R}_{3} \mathrm{POM}^{3+}$ complexes, and about $90 \mathrm{kcal} \mathrm{mol}^{-1}$ in $\mathrm{NMe}_{2}$ vs. $\mathrm{NO}_{2}$ para-substituted pyridine complexes [9]). Replacement of Me by larger and more polarizable Alkyl groups may therefore also modulate the sequence of binding affinities. The comparison of $t$-Bu-anisole and amide ligands indicates that cation encapsulation at the lower rim of calixarene derivatives (e.g. of amide, ester or phosphoryl type) [25-28] results from a significant participation (from 40 to $50 \%$ ) of the calixarene moiety, including the stabilizing role of 'upper rim' remote substituents.

Regarding the phenyl vs. alkyl substituent effects in the $\mathrm{R}_{3} \mathrm{PO}, \mathrm{R}_{3} \mathrm{PS}$ or $\mathrm{R}_{2} \mathrm{PS}_{2}^{-}$ligands, the more polarizable aryl substituents are intrinsically better than alkyl ones in the absence of other competing interactions. However, in the presence of counterions, this order is reversed with $R_{3} P S$ and $\mathrm{R}_{2} \mathrm{PS}_{2}^{-}$ligands, the alkyl substituted ligands being preferred. Concerning the alkyl vs. $O$-alkyl substituent effect in $\mathrm{R}_{3} \mathrm{PO}$ complexes, we find that counterions amplify the preference of alkyl substituted ligands [12,13]. Thus, our study shows clearly that counterions have a very strong influence on the ligand-metal interactions, which means that any data regarding the ligand alone, like intrinsic ligand basicity, is insufficient to assess its interactions in condensed phases where the first coordination sphere is saturated. The counterion effects are expected to increase with more bulky or bidentate anions (nitrate, phosphate, carboxylate, etc.). Furthermore, the stoichiometry of the complexes, as well as the coordination of other species (e.g. solvent molecules) to the metal are additional environmental effects that may modify ligand-metal interactions. Thus, care should be taken in the analysis of such interactions in condensed phases solely in terms of the characteristics of the partners (donor-acceptor, acid-base HSAB [29-32], etc.). Ligand-metal interactions depend on medium effects as well as on other interactions in the first coordination sphere ('steric effects'). Intrinsic basicities, as determined by the gas phase protonation energies (see $E_{\text {prot }}$ values in Figs. 1-3, and plot in Fig. 5) may not properly reflect trends in condensed phases.

These counterion and environment effects may play an important role in the design of ionophores. Marked modulation of stabilities and selectivities may be expected when, for topological reasons (preorganisation, cooperativity effects,...), the binding sites of the ligand wrap around the metal sufficiently to prevent direct coordination of counterions to the metal.

Ion complexation in solution is a much more complicated process, compared to the gas phase. Its thermodynamics depends on enthalpic and entropic contributions involving large numbers of configurations of uncomplexed and complexed states. Ion-ligand interactions compete with large changes in solvation properties. Thus, cumulative dynamic effects arising from multiple ligand, solvent and counterion coordination to the cation need to be incorporated in the simulated system. This can be achieved in principle by combining a QM representation of the 'core' of the system (e.g. the cation's first coordination sphere) with simpler models (e.g. of force field type) for the remaining system $[33,34]$, but remains a challenge for simulation methods.

\section{Acknowledgements}

The authors are grateful to the EU for support (Marie Curie grant for CB, Contract Nos. F14W-CT98-5003 and F14WCT0022), and to the IDRIS and Universite Louis Pasteur for allocation of computer resources. MB, FB, NM 
and RS are grateful to the French Ministry of Research for a grant.

\section{References}

[1] J.M. Lehn, Struct. Bonding 161 (1973) 1-69.

[2] J.-C. Bünzli, D. Wessner, Coord. Chem. Rev. 60 (1984) 191-253.

[3] V. Alexander, Chem. Rev. 95 (1995) 273-342.

[4] I.-H. Chu, H. Zhang, D. Dearden, J. Am. Chem. Soc. 115 (1993) $5736-5744$.

[5] P. Kebarle, Ann. Rev. Phys. Chem. 28 (1977) 445-476.

[6] P. Kollman, J. Am. Chem. Soc. 99 (1977) 4875.

[7] K. Morokuma, Acc. Chem. Res. 10 (1977) 294.

[8] M. Badertscher, M. Welti, P. Portmann, E. Pretsch, Topics Curr. Chem. 136 (1986) 17, and references cited.

[9] F. Berny, N. Muzet, L. Troxler, A. Dedieu, G. Wipff, Inorg. Chem. 38 (1999) 1244-1252.

[10] L. Troxler, A. Dedieu, F. Hutschka, G. Wipff, J. Mol. Struct. (THEOCHEM) 431 (1998) 151-163.

[11] C. Boehme, G. Wipff, J. Phys. Chem. A 103 (1999) 6023-6029.

[12] C. Boehme, G. Wipff, Inorg. Chem. 38 (1999) 5734-5741.

[13] R. Schurhammer, V. Erhart, L. Troxler, G. Wipff, J. Chem. Soc., Perkin Trans. (1999) 2515-2534.

[14] M.J. Frisch, G.W. Trucks, H.B. Schlegel, P.M.W. Gill, B.G. Johnson, M.A. Robb, J.R. Cheeseman, T. Keith, G.A. Petersson, J.A. Montgomery, K. Raghavachari, M.A. Al-Laham, V.G. Zakrzewski, J.V. Ortiz, J.B. Foresman, C.Y. Peng, P.Y. Ayala, W. Chen, M.W. Wong, J.L. Andres, E.S. Reploge, R. Gomperts, F.D.J. Martin, J.S. Binkley, D.J. Defrees, J. Baker, J.P. Stewart, M. Head-Gordon, C. Gonzales, J.A. Pople, Gaussian 94, Rev. B.2, Gaussian, Pittsburgh, PA, 1995.

[15] M.J. Frisch, G.W. Trucks, H.B. Schlegel, G.E. Scuseria, M.A. Robb, J.R. Cheeseman, V.G. Zakrzewski, J.A. Montgomery Jr., R.E. Stratmann, J.C. Burant, S. Dapprich, J.M. Millam, A.D. Daniels, K.N. Kudin, M.C. Strain, O. Farkas, J. Tomasi, V. Barone, M. Cossi, R. Cammi, B. Mennucci, C. Pomelli, C. Adamo, S. Clifford, J. Ochterski, G.A. Petersson, P.Y. Ayala, Q. Cui, K. Morokuma, D.K. Malick, A.D. Rabuck, K. Raghavachari, J.B. Foresman, J. Cioslowski, J.V. Ortiz, B.B. Stefanov, G. Liu, A. Liashenko, P. Piskorz, I.
Komaromi, R. Gomperts, R.L. Martin, D.J. Fox, T. Keith, M.A. Al-Laham, C.Y. Peng, A. Nanayakkara, C. Gonzalez, M. Challacombe, P.M.W. Gill, B. Johnson, W. Chen, M.W. Wong, J.L. Andres, C. Gonzalez, M. Head-Gordon, E.S. Replogle, J.A. Pople, Gaussian 98, Rev. A.5, Gaussian, Pittsburgh, PA, 1998.

[16] M. Dolg, H. Stoll, A. Savin, H. Preuss, Theoret. Chim. Acta 75 (1989) 173

[17] M. Dolg, H. Stoll, A. Savin, H. Preuss, Theoret. Chim. Acta 85 (1993) 441.

[18] A.W. Ehlers, M. Böhme, S. Dapprich, A. Gobbi, A. Höllwarth, V. Jonas, K.F. Köhler, R. Stegmann, A. Veldkamp, G. Frenking, Chem. Phys. Lett. 208 (1993) 111.

[19] T.H. Dunning, P.J. Hay, in: Modern Theoretical Chemistry, Plenum, New York, 1976, pp. 1-28.

[20] S.F. Boys, F. Bernardi, Mol. Phys. 19 (1970) 553-566.

[21] G.Y.S. Chan, M.G.B. Drew, M.J. Hudson, N.S. Isaacs, P. Byers, C. Madic, Polyhedron 15 (1996) 3385-3398.

[22] C. Hill, C. Madic, P. Baron, M. Ozawa, Y. Tanaka, J. Alloys Comp. 271-273 (1998) 159-162.

[23] Y. Zhu, Radiochimica Acta 68 (1995) 95-98.

[24] G. Modolo, R. Odoj, Solv. Extract. Ion Exch. 17 (1999) 33-53.

[25] A. Arduini, E. Ghidini, A. Pochini, R. Ungaro, G.D. Andreetti, G. Calestani, F. Ugozzoli, J. Inclus. Phenom. 6 (1988) 119-134.

[26] M.R. Yaftian, M. Burgard, D. Matt, C.B. Dieleman, F. Rastegar, Solv. Extract. Ion Exch. 15 (1997) 975-989.

[27] J.F. Malone, D.J. Marrs, A. McKervey, P. O'Hagan, N. Thompson, A. Walker, F. Arnaud-Neu, O. Mauprivez, M.-J. Schwing, J.-F. Dozol, H. Rouquette, N. Simon, J. Chem. Soc. Chem. Commun. (1995) 2151-2153.

[28] F. Arnaud-Neu, J.K. Browne, D. Byrne, D.J. Marrs, M.A. McKervey, P. O'Hagan, M.-J. Schwing-Weill, A. Walker, Chem. Eur. J. 5 (1999) 175-186.

[29] R.G. Pearson, Coord. Chem. Rev. 100 (1990) 403-425.

[30] Y. Marcus, Ion Solvation, Wiley, Chichester, 1985.

[31] A.E. Martell, R.D. Hancock, Metal Complexes in Aqueous Solutions, Plenum Press, New York, 1996.

[32] R.D. Hancock, A.E. Martell, Chem. Rev. 89 (1989) 1875-1914.

[33] M.A. Thompson, E.D. Glendening, D. Feller, J. Am. Chem. Soc. 116 (1994) 10465-10476.

[34] J. Gao, Acc. Chem. Res. 29 (1996) 298-305. 